\title{
Mid-Term Outcomes Following Endovascular Re-Intervention for Iliac Artery In-Stent Restenosis
}

\author{
Usman Javed, MD ${ }^{1}$, Christopher R. Balwanz, MD ${ }^{1}$, Ehrin J. Armstrong, MD, MSC ${ }^{1}$, Khung- \\ Keong Yeo, MBBS ${ }^{1}$, Gagan D. Singh, MD ${ }^{1}$, Satinder Singh, MD ${ }^{1}$, David Anderson, BA ${ }^{1}$, \\ Gregory G. Westin, BA ${ }^{1}$, William C. Pevec, MD², and John R. Laird, MD, FSCAI ${ }^{1}$, \\ ${ }^{1}$ Division of Cardiovascular Medicine and The Vascular Center, Davis Medical Center, University \\ of California, Sacramento, California \\ ${ }^{2}$ Division of Vascular and Endovascular Surgery and The Vascular Center, Davis Medical Center, \\ University of California, Sacramento, California
}

\begin{abstract}
Objectives-We sought to evaluate the procedural characteristics and clinical outcomes of endovascular repair for iliac artery (IA) in-stent restenosis (ISR).

Background-An increasing percentage of patients with complex IA occlusive disease are treated with an endovascular approach, but the outcomes of IA-ISR have not been well described.

Methods-We analyzed all endovascular procedures for treatment of IA-ISR performed at our institution between July 2006-December 2010. The primary outcome was primary patency, defined as $<50 \%$ stenosis as assessed by clinical examination and duplex ultrasonography (DUS).
\end{abstract}

Results-Forty-one lesions in 24 patients who underwent repeated endovascular intervention for treatment of IA-ISR. Most lesions were unilateral and involved the common IA (66\%). The mean length of ISR was $30.1 \pm 14.1 \mathrm{~mm}$ with type I (focal) and II (diffuse) ISR occurring with the greatest frequency (34\% and 39\%, respectively). All patients underwent balloon angioplasty; adjunctive stenting zwas performed in $27(66 \%)$ of the lesions. Type II ISR lesions more frequently required stenting (13/16 lesions, $P=0.02$ compared with other patterns of ISR). Procedural success was $100 \%$ with a mean gain of 0.13 in the ankle-brachial index $(P=0.001)$. The 6-and 12-month primary patency rates were $96 \%$ and $82 \%$, respectively. The 12 -month primary-assisted patency rate was $90 \%$ with clinically driven target lesion revascularization (TLR) in three patients.

Conclusions-Endovascular treatment of IA-ISR using an approach of balloon angioplasty followed by selective stenting is associated with high-patency rates and low rates of TLR at 1 year.

\section{Keywords}

peripheral arterial disease; iliac artery; in-stent restenosis

\footnotetext{
(c) 2013 Wiley Periodicals, Inc.

"Correspondence to: John R. Laird, Division of Cardiovascular Medicine and The Vascular Center, University of California, Davis Medical Center, 4860 Y Street, Suite 3400, Sacramento, California 95817. john.laird@ucdmc.ucdavis.edu.

Disclosure: John R. Laird: Consultant/Advisory Board Member for Abbott Vascular, Bard Peripheral Vascular, Boston Scientific, Covi dien, and Medtronic; research support from W.L. Gore and Atrium Medical.

Conflict of interest: Nothing to report.
} 


\section{INTRODUCTION}

Percutaneous transluminal angioplasty (PTA) followed by primary or selective stenting is routinely used to treat iliac artery (IA) occlusive disease [1-9]. The TransAtlantic InterSociety Consensus (TASC) II working group has published guidelines for the management of peripheral arterial disease (PAD). This consensus statement recommends endovascular intervention for TASC A and B lesions [10]. Several recent studies have also advocated endovascular intervention for increasingly complex IA lesions, including TASC $\mathrm{C}$ and D lesions [11-14]. IA in-stent restenosis (IA-ISR) occurs with a frequency of up to $10 \%$ at 1 year and is more common at longer term follow-up and with more complex lesions $[15,16]$.

Despite the large number of IA interventions being performed and the relative frequency of this problem, there is a paucity of data pertaining to lesion characteristics or clinical and procedural outcomes among patients with IA-ISR. The aim of this study was to identify patient and angiographic characteristics associated with the need for IA-ISR intervention as well as the procedural and clinical outcomes after endovascular treatment of IA-ISR.

\section{METHODS}

\section{PAD-UCD Registry}

The PAD-UCD Registry consists of all patients with a clinical diagnosis of PAD who underwent diagnostic angiography or therapeutic endovascular intervention at the University of California, Davis Medical Center beginning in 2006. Three vascular surgeons and one interventional cardiologist performed these procedures during the study period. For this study, the subset of patients in the registry with IA-ISR was analyzed. The study protocol was approved by the Institutional Review Board at UC Davis Medical Center.

\section{Data Collection and Definitions}

Data from 24 patients (32 limbs and 41 lesions) were retrospectively analyzed from review of electronic medical record documentation. Pre- and post-procedure clinical notes, admission history, and physical examination documentation were used to identify clinical presentation as well as post-procedure outcomes and medical management. The category of limb ischemia was defined by using the Rutherford classification [17].

Ankle-brachial pressure index (ABI) measurements and duplex ultrasound (DUS) were obtained in all patients before endovascular treatment and at follow-up. Clinical indications for repeat intervention included recurrent symptoms accompanied by either $\searrow 0.10$ decrease in ABI or recurrent stenosis $>50 \%$ confirmed by DUS (peak systolic velocity ratio of $\geq 2.0$ ) [18]. All patients were pretreated with aspirin $325 \mathrm{mg}$ as well as a clopidogrel 300-mg loading dose prior to the procedure. Post-procedure antiplatelet therapy consisted of aspirin daily for life at a dose of 81-325 mg daily and clopidogrel $75 \mathrm{mg}$ daily for at least 3 months.

Two board-certified cardiologists with experience in peripheral angiography (EA and UJ) reviewed all angiographic images to verify lesion morphology and characteristics, TASC II classification, presence of thrombus, and status of the distal run-off vessels. Quantitative angiography was performed to evaluate the pre- and postintervention minimal lumen diameter, percent diameter stenosis, lesion length, and reference vessel diameter using quantitative vascular analysis (Philips Xcelera, Philips, Amsterdam, the Netherlands). Instent restenosis was defined as type I (focal, lesion length $\leq 30 \mathrm{~mm}$ ), type II (diffuse, >30 $\mathrm{mm}$ long but within the stent), type III (proliferative, $>30 \mathrm{~mm}$ and extending beyond the stent edge), and type IV (total occlusion; Fig. 1) [19]. Procedural data collection included the type of intervention (standard balloon angioplasty, cutting balloon angioplasty, stenting 
(bare or covered), and rarely thrombolysis or thromboaspiration. Procedural success was defined as $<30 \%$ stenosis at the conclusion of procedure with less than $10 \mathrm{mmHg}$ peak gradient. Iliac stents were deployed selectively for initial PTA failure due to residual stenosis ( $30 \%$ ) or a pressure gradient of $\geq 10 \mathrm{mmHg}$.

Hemodynamic success and clinical improvement (an improvement by at least one clinical category on the Rutherford scale plus a change in ABI >0.10) were defined using the Society for Vascular Surgery and the International Society for Cardiovascular Surgery reporting standards [20]. Patients were routinely seen 30 days after the revascularization procedure. Clinical improvement was determined based on history and noninvasive vascular laboratory tests. Postoperative follow-up, consisting of a clinical and serial DUS examination, was conducted every 6 months during the first postoperative year and every 612 months thereafter. Lesion post-procedure outcomes were determined by clinical followup and DUS surveillance performed at 1, 6, and 12 months.

Patency and limb salvage rates were determined longitudinally at the most recent examination. Primary patency was defined as a patent artery or stent (after intervention for the restenosis) without recurrent restenosis or the need for further intervention. Vessel patency was evaluated with serial ABI and toe-brachial index (TBI) measures and DUS at 0-30 days, 4-6 months, and 9-12 months. Loss of patency was defined as the presence of $>50 \%$ restenosis at the treatment site (peak systolic velocity ratio $>2.0$ ), or by target lesion revascularization (TLR). Major amputation was defined as any amputation above the level of the ankle joint.

Patient-specific major adverse cardiovascular events (MACE), defined as death, myocardial infarction, stroke, or major amputation were identified through electronic documentation of clinic or inpatient notes as well as the Social Security Death Index.

\section{Outcomes}

The primary end point was primary patency $(<50 \%$ stenosis by DUS or angiographic assessment). Secondary outcomes included primary-assisted patency (primary patency or patency after repeat intervention for restenosis), TLR, and ipsilateral limb loss or amputation. These events were assessed at regular intervals (0-30 days, 4-6 months, and 912 months post-procedure). Other secondary end points included the occurrence of any major adverse cardiovascular events (MACE), defined as death, myocardial infarction, stroke, or major amputation.

\section{Data Analysis}

Median values with interquartile ranges were used to describe continuous variables, and numerical values (percentages) were used for categorical variables. Univariate analysis was used to identify predictors of restenosis. Continuous variables were compared using the Kruskal-Wallis test. Categorical values were compared by the chi-square or Fisher's exact test. Freedom from binary restenosis and freedom from TLR at 1, 6, and 12 months were analyzed with the use of Kaplan- Meier survival estimates and the log-rank test. Analysis of the change in ABI indices and TLR over time was performed using a hierarchic longitudinal mixed-model analysis. The interaction between the treatment and intervention date was used to determine if there were differences in the treatment slopes over time for the linear ABI model. The small number of TLR cases precluded investigation of any interaction in the logistic model.

All tests were performed using two-sided tests, and the critical value for statistical significance was set at a value of $<0.05$. Analyses were conducted using JMP (SPSS, Chicago, IL) and STATA Version 11.2 (STATA Corporation, College Station, TX). All 
authors had full access to and take full responsibility for the integrity of the data. All authors have read and agree to the manuscript as written.

\section{RESULTS}

During the study period, 125 patients (174 limbs) underwent angioplasty and stenting for IA stenosis. Among these, 24 patients had IA-ISR requiring repeat intervention in 41 lesions. The initial indication for stent placement in these 24 patients was claudication in 14 patients, and critical limb ischemia in the other 10 patients. The mean stent length at the time of initial implantation was $47 \pm 13 \mathrm{~mm}$, and the time from initial intervention to treatment for IA-ISR was $12.5 \pm 6.7$ months. One patient who initially underwent stent placement for claudication required treatment of IA-ISR for critical limb ischemia occurring 3 years after the initial intervention, and two patients initially treated for critical limb ischemia presented with IA-ISR manifesting as acute limb ischemia. All other patients presented with the same or lower Rutherford classification during treatment of IA-ISR as their initial intervention.

Patient indices and procedural details are summarized in Tables I and 2. The mean age was 58.5 years with predominant female gender $(68 \%)$. More than half of the patients were actively smoking and a majority of the patients were taking aspirin and/or clopidogrel at the time of IA-ISR. The mean LDL was $75 \pm 33 \mathrm{mg} / \mathrm{dL}$.

The indication for revascularization of IA-ISR included critical limb ischemia in 5 patients (21\%), severe claudication in 13 patients (54\%), and acute limb ischemia in 2 patients (8\%). Four patients (17\%) were asymptomatic but had reintervention performed to maintain vessel patency and minimize limb threat after DUS suggested significant restenosis accompanied by a decrease in ABI.

The majority of the lesions were unilateral (75\%) and involved the common iliac arteries (67\%). The mean ISR length was $30.1 \mathrm{~mm}$. Types I and II ISR patterns were the most frequent subtypes (34\% and 39\%, respectively), and these were seen with similar prevalence in the common and external IA (Fig. 2). On univariate analysis, there was no statistically significant association between gender, age, diabetes, smoking status, or patency rates with a specific subtype of ISR.

Procedural success was achieved in $100 \%$ of cases. The overall procedural complication rate was $4.2 \%$, as one patient with a subacute occlusion of a left common iliac stent sustained distal embolization to the left common femoral artery that required surgical embolectomy. That patient subsequently did well and did not have recurrent restenosis at one year. All patients underwent initial balloon angioplasty, and 66\% required adjunctive stenting, with subsequent placement of 19 covered stents and 8 bare metal stents. Post-procedure, there was a net gain of 0.11 in ABI $(P=0.029)$. Figure 3 shows an example of bilateral common iliac ISR treated successfully with balloon-expandable covered stents.

The mean run off score was $2.1 \pm 0.8$. There was no relationship between distal runoff and TLR. Five patients underwent intervention to infrainguinal vessels during the same procedure for IA-ISR. All of these patients had critical limb ischemia and the distal interventions were performed to improve outflow and maximize the probability of limb salvage.

The 6- and 12-month primary patency rates were $96 \%$ (95\% CI: 76-98\%) and 82\% (95\% CI: 61-93\%), respectively. The 12-month primary-assisted patency rate was 90\%. The TLR rate was 10\% at 12-month follow up (Figs. 4 and 5). 
Of the three patients who underwent further reintervention, two patients had a balloon angioplasty as initial treatment for IA-ISR and were subsequently treated with covered balloon-expandable stents due to diffuse ISR. The third patient was initially treated with repeat stenting for IA-ISR and then subsequently treated with balloon angioplasty alone due to a focal restenotic lesion.

The overall survival rate was $95 \%$ at 12 months with no limb loss. One patient died of sepsis and the other from sudden cardiac death (both unrelated to the procedure). There were no other major adverse cardiovascular events during the follow-up period.

\section{DISCUSSION}

Stenting has become increasingly common in the endovascular treatment of IA disease, as stents improve the early outcomes after suboptimal or failed PTA [21-26]. Prior studies of selective IA stenting for de novo lesions have reported a wide range of long-term primary patency rates ranging from $59-86 \%$ at 3 years to $49-75 \%$ at 5 years, indicating that IA- ISR is frequently encountered during long-term follow up [7,15,25-30]. However, the optimal treatment for IA-ISR remains uncertain. In this study, we describe excellent mid-term results after endovascular treatment of IA-ISR.

Several patient and procedural variables have previously been associated with lower rates of restenosis after IA stenting. These include absence of diabetes, smoking, or renal insufficiency, short and less complex lesions, larger vessel diameter, lesion location (common IA vs. external IA), and intervention driven by claudication versus CLI as well as possibly younger age [29,31-33]. However, Davies et al. [33] recently reported that recurrence of iliac disease after initial intervention was associated with younger age and female gender, likely due to smaller vessel diameter. Our current cohort had many favorable characteristics including a relatively low prevalence of diabetes and renal insufficiency, young age, short lesion length, and lesions that were predominantly TASC A/B and ISR type I/II. Contrary to prior studies, IA-ISR in this series occurred in subjects who otherwise would be considered at "low risk" for IA-ISR. However, 63\% of the subjects were women, supporting the possible role of gender in IA restenosis.

Earlier studies such as Kropman et al. used primarily angioplasty alone to treat in-stent restenosis (only $14 \%$ of lesions had stent replacement) while Davies et al. and this study utilized adjunctive stenting in $70 \%$ and $66 \%$ of the lesions, respectively. Of note, all three of these studies reported primary patency rates $>80 \%$ at 1 year and primary-assisted patency rates $>90 \%$ at 1 year, suggesting overall excellent results of endovascular intervention for IA-ISR [33,34].

In comparison with infrainguinal endovascular interventions, the treatment for IA-ISR is conventionally limited to balloon/cutting balloon angioplasty or stenting, as other modalities such as laser, rotational, and directional atherectomy techniques are not routinely employed. The current data are too limited to identify the superiority of a particular modality for treatment of IA-ISR. In a retrospective analysis of 14 IA-ISR lesions in 12 patients, Tsetis et al. [35] demonstrated $100 \%$ primary patency at a mean follow-up of approximately 2 years with cutting balloon angioplasty. In our series, the utilization of cutting balloon angioplasty was lower without significant differences among the various ISR classifications.

Schurmann et al. [9] previously reported long-term outcomes of 110 patients who underwent stent placement for occlusive IA disease. During a mean follow-up of 5.8 years, 23 patients underwent repeat endovascular intervention for restenosis, and 9 of those 23 patients required repeat stent placement. Subsequently, 12 of those 23 patients developed recurrent restenosis prompting another endovascular intervention or surgery. Procedural and lesion 
characteristics were not reported, nor were the outcomes comparing PTA and restenting. All of the IA-ISR lesions in our series were initially treated with standard PTA, and selective restenting after unsatisfactory PTA was performed in $66 \%$ of the lesions. Although type 2 ISR lesions were more likely to require stenting (13 of 16 lesions), the overall benefit of stenting could not be discerned among various patterns of ISR due to small numbers in each group. However, given the high rate of stenting $(66 \%)$ required after initial suboptimal angioplasty, our experience suggests that repeat stenting is often required for IA-ISR rather than PTA alone.

There is increasing evidence regarding utilization of covered stents in peripheral interventions [36]. Covered stents may lower the incidence of ISR by excluding plaque and endothelium as well as preventing the migration and proliferation of vascular smooth muscle and inflammatory cells through the stent struts [37]. In our current series, $27(65.7 \%)$ of the IA-ISR lesions required restenting, and covered stents were placed in 19 of those lesions. The COBEST trial found that for complex, de novo IA lesions (TASC C and D), implantation of a covered stent was associated with significantly less binary restenosis at 18 months compared to uncovered stents, and there was a trend towards less stent occlusion [14]. However, the superiority of covered stenting compared with uncovered stent placement has not yet been proven for IA-ISR treatment. In a recent analysis of femoral-popliteal ISR treatment with excimer laser atherectomy and PTA followed by implantation of VIABAHN Endoprosthesis, a modest primary patency rate of $48 \%$ was reported; however, the TLR was low at $17.4 \%$ [38]. Our analysis did not demonstrate a difference in patency between placement of a covered stent versus an uncovered stent or any stent versus PTA, but this subgroup analysis was limited by small overall size of the cohort.

In our current series, the endovascular treatment of IA-ISR was associated with a high procedural success of $100 \%$ and a low rate of procedural complications (4.2\%), which compares favorably with results in the primary endovascular repair of IA disease $[2,7,15,25,29-31,33,34]$. Despite the fact that more than $29 \%$ of the patients presented with acute or critical limb ischemia, there was no limb loss or need for surgical revision at 1 year. A minority of patients underwent revascularization primarily due to the findings on DUS, with a goal of maintaining patency of the IA. Progression to total occlusion may make subsequent intervention more complex with a higher likelihood of failure or complications. The high primary and primary-assisted patency rates seen in this series underscore endovascular repair as a viable option for IA-ISR.

The results of this study should be interpreted in the context of its design. The series is a single-center, retrospective study and thus has inherent limitations. There was a potential selection bias in patient selection for endovascular intervention, but in general, our clinical practice is to reintervene only in the presence of symptoms and documented restenosis by noninvasive techniques. As the number of procedures was small, this study lacks sufficient statistical power to make conclusions on the comparative effectiveness of a particular endovascular modality and therefore the results may not be fully generalizable. Long-term follow-up with a larger sample size will be helpful to determine the relative contribution of different ISR patterns to long-term patency.

\section{CONCLUSIONS}

In summary, mid-term results of endovascular repair for IA-ISR with PTA and selective restenting show acceptable mid-term patency rates and offer a viable alternative to conventional surgical bypass. Further studies are indicated to assess long-term outcomes and optimal procedural strategies for IA-ISR. 


\section{REFERENCES}

1. Vorwerk D, Guenther RW, Schurmann K, Wendt G, Peters I. Primary stent placement for chronic iliac artery occlusions: Follow-up results in 103 patients. Radiology. 1995; 194:745-749. [PubMed: 7862973]

2. Tetteroo E, van der Graaf Y, Bosch JL, van Engelen AD, Hunink MG, Eikelboom BC, et al. Randomised comparison of primary stent placement versus primary angioplasty followed by selective stent placement in patients with iliac-artery occlusive disease. Dutch Iliac Stent Trial Study Group. Lancet. 1998; 351(9110):1153-1159. [PubMed: 9643685]

3. Rees CR, Palmaz JC, Garcia O, Roeren T, Richter GM, Gardiner G Jr, et al. Angioplasty and stenting of completely occluded iliac arteries. Radiology. 1989; 172:953-959. [PubMed: 2528170]

4. Dyet JF, Gaines PA, Nicholson AA, Cleveland T, Cook AM, Wilkinson AR, et al. Treatment of chronic iliac artery occlusions by means of percutaneous endovascular stent placement. J Vasc Interv Radiol. 1997; 8(3):349-353. [PubMed: 9152906]

5. Yedlicka JW Jr, Ferral H, Bjarnason H, Hunter DW, Castaneda-Zuniga WR, Amplatz K. Chronic iliac artery occlusions: Primary recanalization with endovascular stents. J Vasc Interv Radiol. 1994; 5(6):843-847. [PubMed: 7873863]

6. Martin EC, Katzen BT, Benenati JF, Diethrich EB, Dorros G, Graor RA, et al. Multicenter trial of the wallstent in the iliac and femoral arteries. J Vasc Interv Radiol. 1995; 6(6):843-849. [PubMed: 8850658]

7. Vorwerk D, Gunther RW, Schurmann K, Wendt G. Aortic and iliac stenoses: Follow-up results of stent placement after insufficient balloon angioplasty in 118 cases. Radiology. 1996; 198(1):45-48. [PubMed: 8539403]

8. Murphy TP, Ariaratnam NS, Carney WI Jr, Marcaccio EJ, Slaiby JM, Soares GM, et al. Aortoiliac insufficiency: Long-term experience with stent placement for treatment. Radiology. 2004; 231(1): 243-249. [PubMed: 15068949]

9. Schurmann K, Mahnken A, Meyer J, Haage P, Chalabi K, Peters I, et al. Long-term results 10 years after iliac arterial stent placement. Radiology. 2002; 224(3):731-738. [PubMed: 12202707]

10. Norgren L, Hiatt WR, Dormandy JA, Nehler MR, Harris KA, Fowkes FG. Inter-society consensus for the management of peripheral arterial disease (TASC II). J Vasc Surg. 2007; 45(Suppl S):S5S67. [PubMed: 17223489]

11. Bosch JL, Hunink MG. Meta-analysis of the results of percutaneous transluminal angioplasty and stent placement for aortoiliac occlusive disease. Radiology. 1997; 204(1):87-96. [PubMed: 9205227]

12. Sixt S, Alawied AK, Rastan A, Schwarzwalder U, Kleim M, Noory E, et al. Acute and long-term outcome of endovascular therapy for aortoiliac occlusive lesions stratified according to the TASC classification: A single-center experience. J Endovasc Ther. 2008; 15(4):408-416. [PubMed: 18729553]

13. Leville CD, Kashyap VS, Clair DG, Bena JF, Lyden SP, Greenberg RK, et al. Endovascular management of iliac artery occlusions: Extending treatment to TransAtlantic Inter-Society Consensus class C and D patients. J Vasc Surg. 2006; 43(1):32-39. [PubMed: 16414384]

14. Mwipatayi BP, Thomas S, Wong J, Temple SE, Vijayan V, Jackson M, et al. A comparison of covered vs bare expandable stents for the treatment of aortoiliac occlusive disease. J Vasc Surg. 2011; 54(6):1561-1570. [PubMed: 21906903]

15. Kudo T, Chandra FA, Ahn SS. Long-term outcomes and predictors of iliac angioplasty with selective stenting. J Vasc Surg. 2005; 42(3):466-475. [PubMed: 16171589]

16. Koizumi A, Kumakura H, Kanai H, Araki Y, Kasama S, Sumino H, et al. Ten-year patency and factors causing restenosis after endovascular treatment of iliac artery lesions. Circ J. 2009; 73(5): 860-866. [PubMed: 19282607]

17. Rutherford RB, Baker JD, Ernst C, Johnston KW, Porter JM, Ahn S, et al. Recommended standards for reports dealing with lower extremity ischemia: Revised version. J Vasc Surg. 1997; 26(3):517-538. [PubMed: 9308598]

18. Bandyk D. Nature and management of duplex abnormalities encountered during infrainguinal vein bypass grafting. J Vasc Surg. 1996; 24:430-438. [PubMed: 8808965] 
19. Tosaka A, Soga Y, Iida O, Ishihara T, Hirano K, Suzuki K, et al. Classification and clinical impact of restenosis after femoropopliteal stenting. J Am Coll Cardiol. 2012; 59:16-23. [PubMed: 22192663]

20. Ahn SS, Rutherford RB, Becker GJ, Comerota AJ, Johnston KW, McClean GK, et al. Reporting standards for lower extremity arterial endovascular procedures. Society for Vascular Surgery/ International Society for Cardiovascular Surgery. J Vasc Surg. 1993; 17:1103-1107. [PubMed: 8505790]

21. Ahn SS, Concepcion B. Indications and results of arterial stents for occlusive disease. World J Surg. 1996; 20(6):644-648. [PubMed: 8662147]

22. Gunther RW, Vorwerk D, Antonucci F, Beyssen B, Essinger A, Gaux JC, et al. Iliac artery stenosis or obstruction after unsuccessful balloon angioplasty: Treatment with a self-expandable stent. Am J Roent Genol. 1991; 156(2):389-393.

23. Palmaz JC, Laborde JC, Rivera FJ, Encarnacion CE, Lutz JD, Moss JG. Stenting of the iliac arteries with the Palmaz stent: Experience from a multicenter trial. Cardiovasc Intervent Radiol. 1992; 15:291-297. [PubMed: 1423389]

24. Vorwerk D, Gunther RW. Stent placement in iliac arterial lesions: Three years of clinical experience with the Wallstent. Cardiovasc Intervent Radiol. 1992; 15:285-290. [PubMed: 1423388]

25. Treiman GS, Schneider PA, Lawrence PF, Pevec WC, Bush RL, Ichikawa L. Does stent placement improve the results of ineffective or complicated iliac artery angioplasty? J Vasc Surg. 1998; 28:104-114. [PubMed: 9685136]

26. Hassen-Khodja R, Sala F, Declemy S, Bouillanne PJ, Batt M, Staccini P. Value of stent placement during percutaneous transluminal angioplasty of the iliac arteries. J Cardiovasc Surg. 2001; 42:369-374. [PubMed: 11398035]

27. Ballard JL, Sparks SR, Taylor FC, Bergan JJ, Smith DC, Bunt TJ, et al. Complications of iliac artery stent deployment. J Vasc Surg. 1996; 24:545-555. [PubMed: 8911403]

28. Timaran CH, Stevens SL, Freeman MB, Goldman MH. External iliac and common iliac artery angioplasty and stenting in men and women. J Vasc Surg. 2001; 34:440-446. [PubMed: 11533595]

29. Murphy KD, Encarnacion CE, Le VA, Palmaz JC. Iliac artery stent placement with the Palmaz stent: Follow-up study. J Vasc Intervent Radiol. 1995; 6:321-329.

30. Becquemin JP, Allaire E, Qvarfordt P, Desgranges P, Kobeiter H, Melliere D. Surgical transluminal iliac angioplasty with selective stenting: Long-term results assessed by means of duplex scanning. J Vasc Surg. 1999; 29:422-429. [PubMed: 10069906]

31. Johnston KW. Iliac arteries: Reanalysis of results of balloon angioplasty. Radiology. 1993; 186:207-212. [PubMed: 8416566]

32. Sullivan TM, Childs MB, Bacharach JM, Gray BH, Piedmonte MR. Percutaneous transluminal angioplasty and primary stenting of the iliac arteries in 288 patients. J Vasc Surg. 1997; 25:829839. [PubMed: 9152310]

33. Davies MG, Bismuth J, Saad WE, Naoum JJ, Peden EK, Lumsden AB. Outcomes of reintervention for recurrent disease after percutaneous iliac angioplasty and stenting. J Endovasc Ther. 2011; 18:169-180. [PubMed: 21521057]

34. Kropman RH, Bemelman M, Vos JA, van den Berg JC, van de Pavoordt HD, van de Mortel RH, et al. Long-term results of percutaneous transluminal angioplasty for symptomatic iliac in-stent stenosis. Eur J Vasc Endovasc Surg. 2006; 32:634-638. [PubMed: 16875851]

35. Tsetis D, Belli AM, Morgan R, Basile A, Kostas T, Manousaki E, et al. Preliminary experience with cutting balloon angioplasty for iliac artery in-stent restenosis. J Endovasc Ther. 2008; 15(2): 193-202. [PubMed: 18426263]

36. Rogers JH, Laird JR. Overview of new technologies for lower extremity revascularization. Circulation. 2007; 116(18):2072-2085. [PubMed: 17967988]

37. Farb A, Sangiorgi G, Carter AJ, Walley VM, Edwards WD, Schwartz RS, et al. Pathology of acute and chronic coronary stenting in humans. Circulation. 1999; 99(1):44-52. [PubMed: 9884378]

38. Laird JR, Yeo KK, Rocha-Singh K, Das T, Joye J, Dippel E, et al. Excimer laser with adjunctive balloon angioplasty and heparin-coated self-expanding stent grafts for the treatment of 
femoropopliteal artery in-stent restenosis: Twelve-month results from the SALVAGE study. Cath Cardiovasc Interv. 2012 Epub 2012/03/17. 


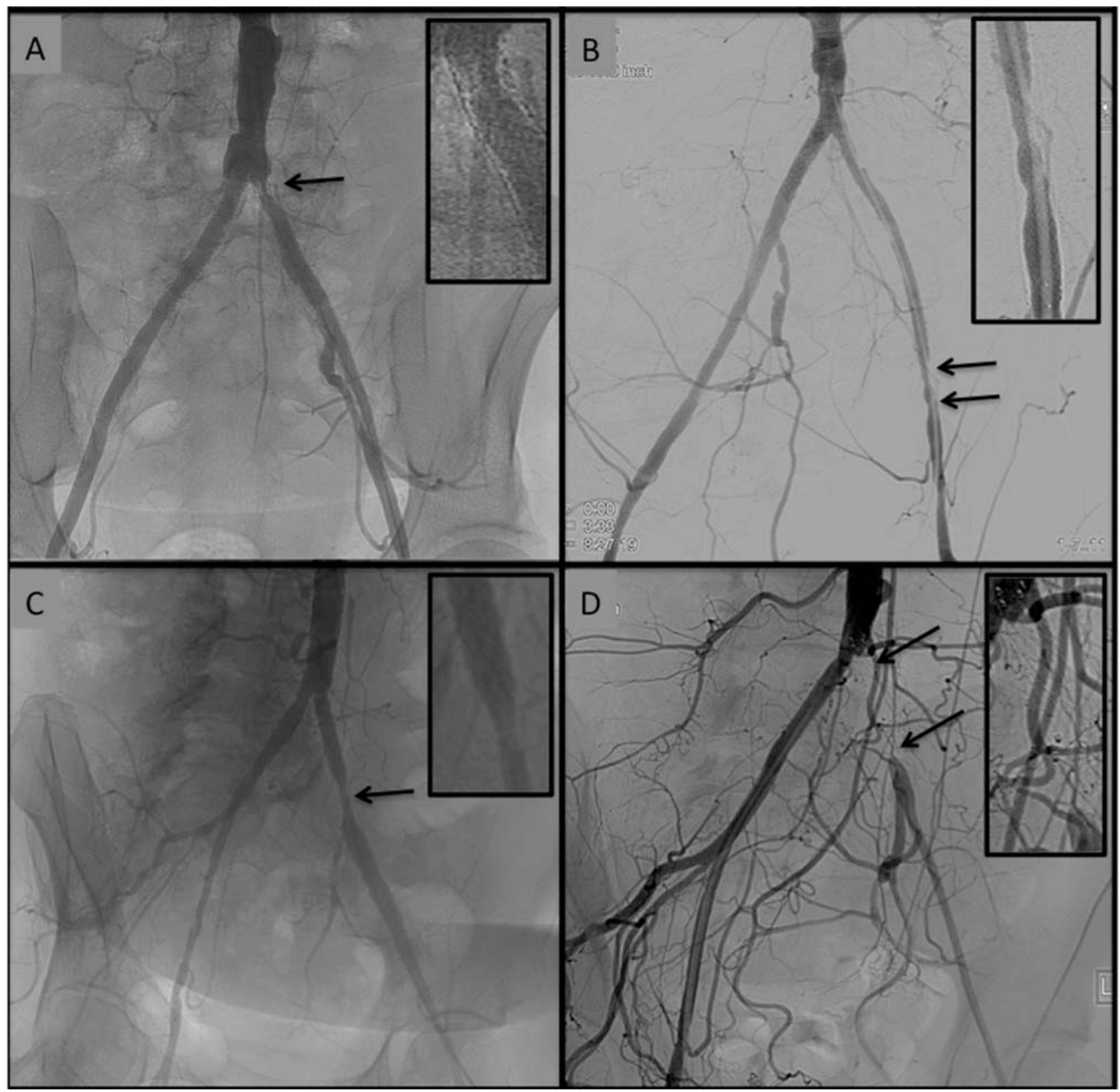

Fig. 1.

Subtypes of iliac artery in-stent restenosis. (a) Type I restenosis showing a focal lesion <30 $\mathrm{mm}$ in length. (b) Type II restenosis showing diffuse hyperplasia $>30 \mathrm{~mm}$ in length. (c) Type III restenosis showing proliferative restenosis extending beyond the stent edge. (d) Type IV restenosis showing complete occlusion of a previously placed stent. Inset panels show magnified views of each ISR pattern. 


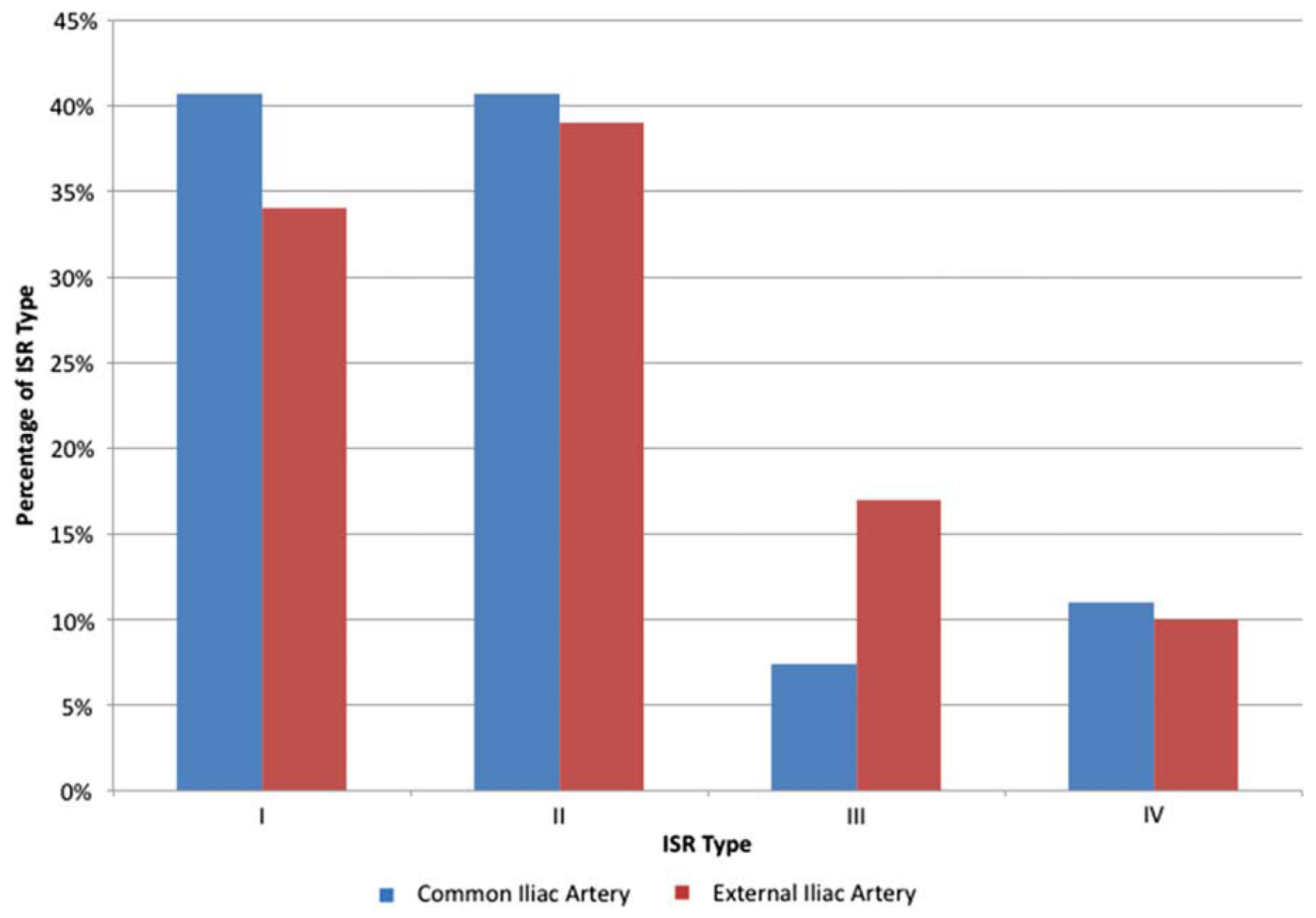

Fig. 2.

Anatomic distribution of lesions by ISR type. 


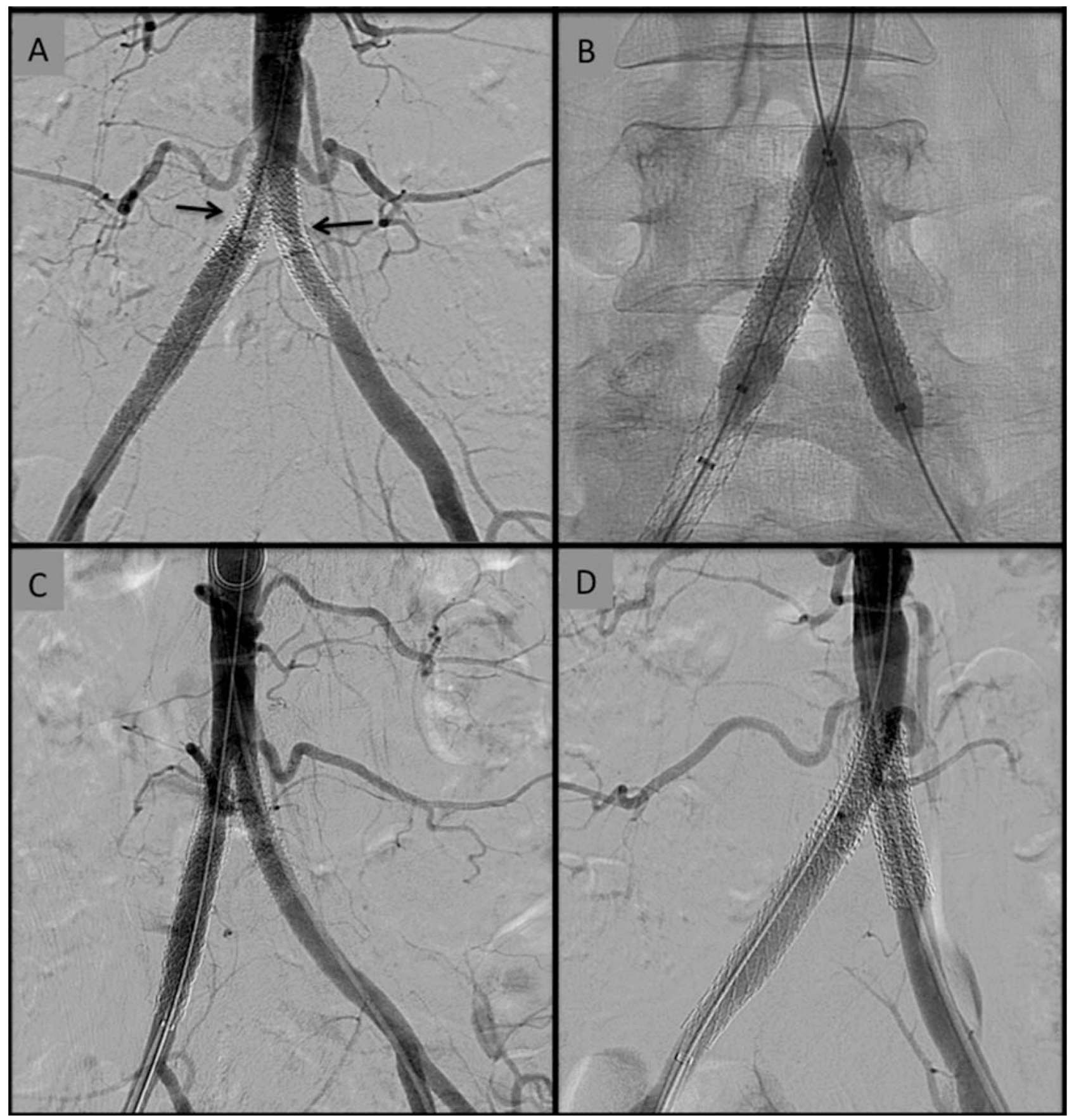

Fig. 3.

Bilateral common iliac artery ISR treated successfully with balloon-expandable covered stents. (a) Bilateral common iliac artery restenosis within two previously placed balloonexpandable noncovered stents. The patient presented with severe claudication despite maximal medical therapy. (b) After initial balloon angioplasty, two balloon-expandable covered stents were simultaneously deployed within the body of the previously placed stents. (c and d) show orthogonal views after stent placement demonstrating excellent angiographic result. Patient remained asymptomatic at 12-month follow-up with no evidence of recurrent ISR by serial duplex ultrasound. 


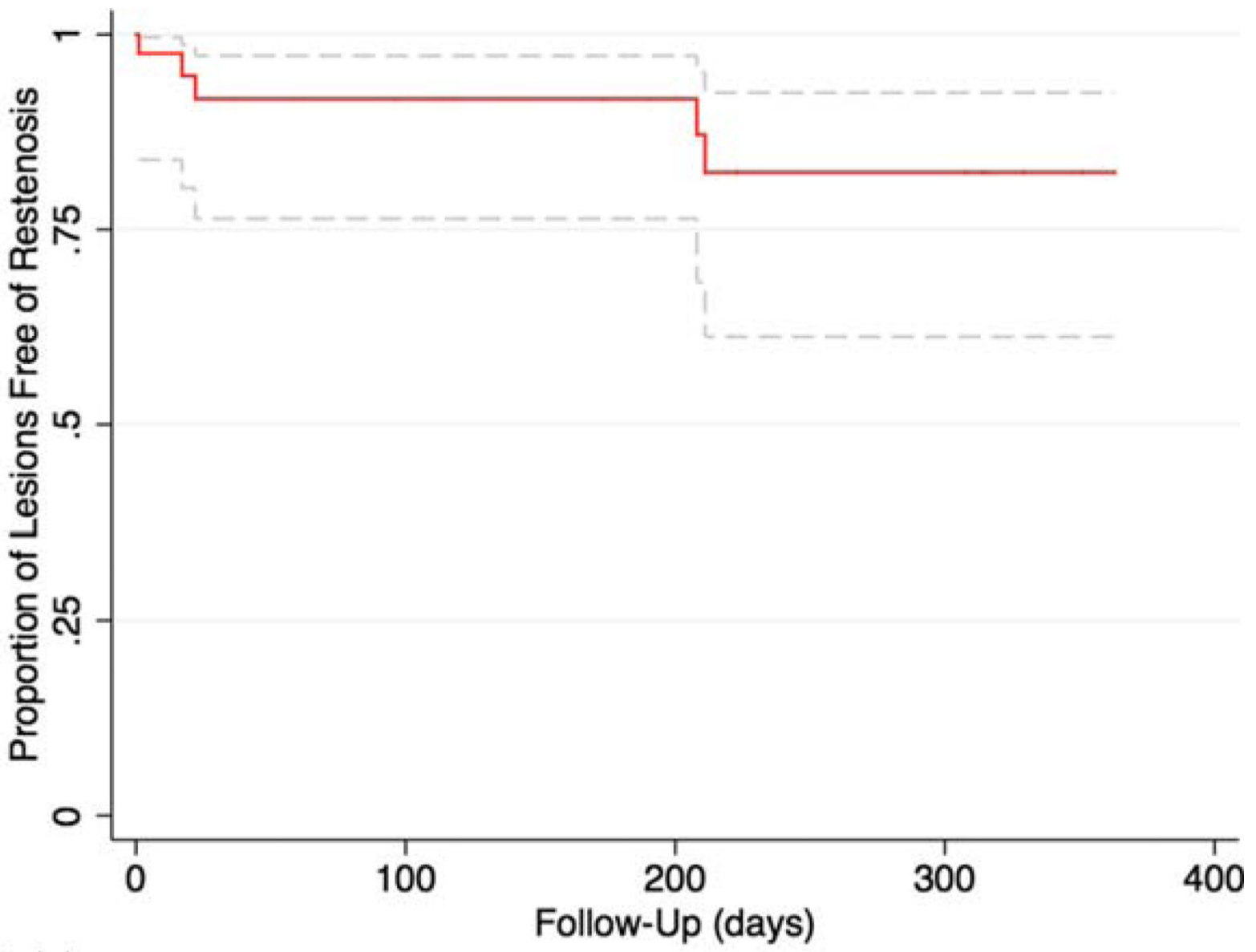

Number at risk

Fig. 4.

Restenosis at 12-month follow-up. 


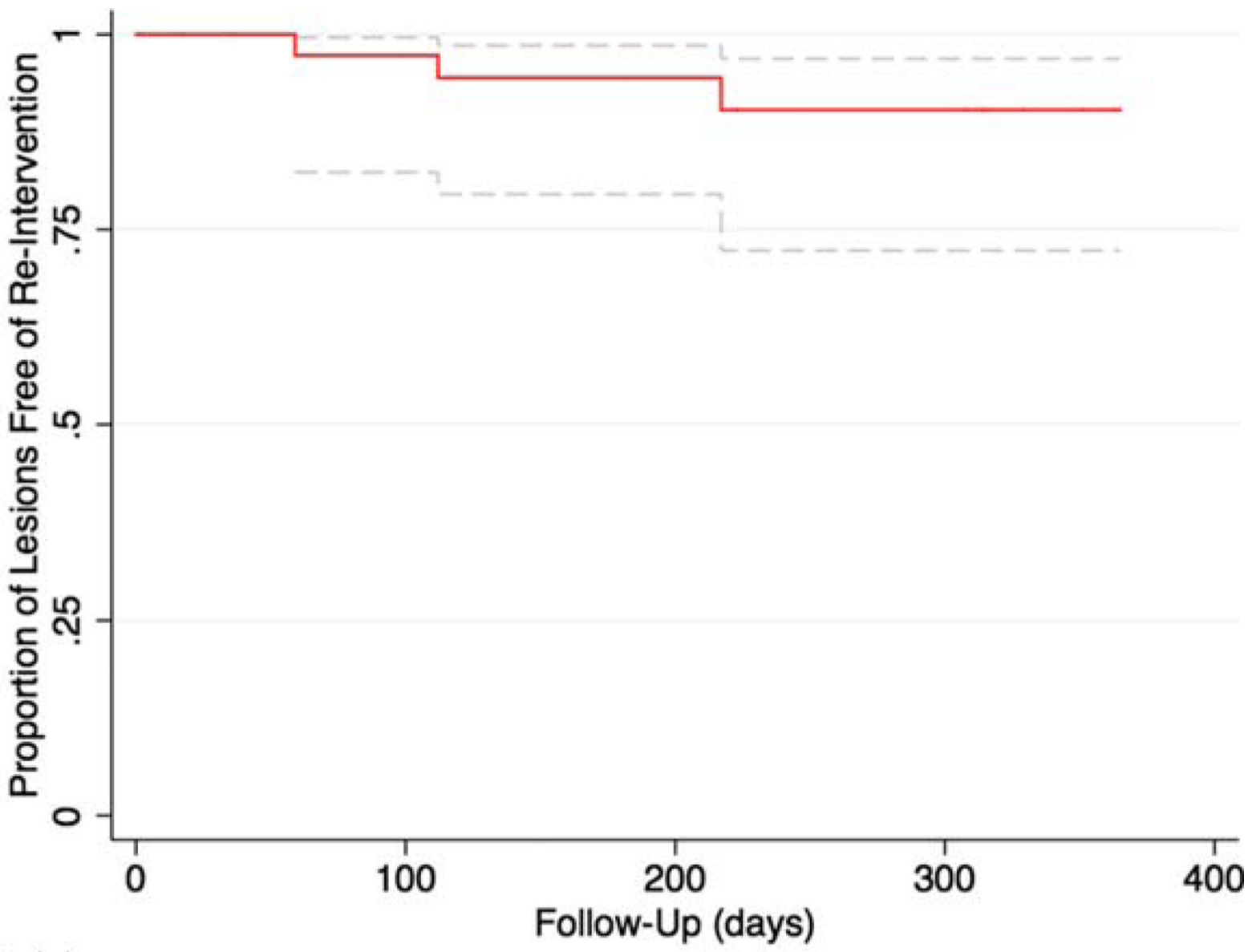

Number at risk

Fig. 5.

TLR at 12-month follow-up. 


\section{TABLE I}

Patient and Clinical Characteristics $(n=24)$

\begin{tabular}{lc}
\hline Age (years, mean \pm SD) & $58.5 \pm 11.1$ \\
Male gender & $9(38 \%)$ \\
DM & $9(38 \%)$ \\
CAD & $9(38 \%)$ \\
Hypertension & $21(88 \%)$ \\
Active smoking & $14(59 \%)$ \\
LDL (mg/dL, mean \pm SD) & $75 \pm 33$ \\
eGFR (mL/min) & $78 \pm 31$ \\
Aspirin & $23(96 \%)$ \\
Clopidogrel & $15(63 \%)$ \\
Dual antiplatelet & $15(63 \%)$ \\
Statin & $20(83 \%)$ \\
Pre-procedure rutherford class & \\
$\leq 3$ & $16(67 \%)$ \\
$\geq 4$ & $8(33 \%)$ \\
Post-procedure rutherford class (30 days) & \\
$\leq 3$ & $19(80 \%)$ \\
$\geq 4$ & $5(20 \%)$ \\
ABI & \\
Pre-procedure (Median, IQR) & \\
Post-procedure 1 month (Median, IQR) & $0.87(0.80,1.01)$ \\
Indication for revascularization of IA-ISR & \\
Acute limb ischemia & $2(8 \%)$ \\
Critical limb ischemia & $5(21 \%)$ \\
Claudication & $13(54 \%)$ \\
Duplex surveillance & $4(17 \%)$ \\
Time from Initial Stent Placement to & $12.5 \pm 6.7$ \\
\hline
\end{tabular}

Catheter Cardiovasc Interv. Author manuscript; available in PMC 2013 December 01. 
TABLE 2

Lesion and Procedural Characteristics $(n=41)$

\begin{tabular}{|c|c|}
\hline \multicolumn{2}{|c|}{ TASC classification of the original procedure } \\
\hline A & $19(46 \%)$ \\
\hline B & $14(34 \%)$ \\
\hline $\mathrm{C}$ & $6(16 \%)$ \\
\hline $\mathrm{D}$ & $2(4 \%)$ \\
\hline \multicolumn{2}{|l|}{ ISR Type } \\
\hline I (focal, <30 mm) & $14(34 \%)$ \\
\hline II (diffuse, > $30 \mathrm{~mm}$ ) & $16(39 \%)$ \\
\hline III (proliferative) & $7(17 \%)$ \\
\hline IV (occlusion) & $4(10 \%)$ \\
\hline $\begin{array}{l}\text { Stent length of initial intervention } \\
(\mathrm{mm}, \text { Mean } \pm \text { SD })\end{array}$ & $47.0 \pm 13.0$ \\
\hline Lesion length (mm, Mean \pm SD) & $30.1 \pm 14.0$ \\
\hline Artery diameter $(\mathrm{mm}, \mathrm{Mean} \pm \mathrm{SD})$ & $7.2 \pm 1.1$ \\
\hline \multicolumn{2}{|l|}{ Lesion location } \\
\hline Common iliac artery & $66 \%$ \\
\hline External iliac artery & $34 \%$ \\
\hline Bilateral disease & $25 \%$ \\
\hline \multicolumn{2}{|l|}{ Intervention performed } \\
\hline Balloon angioplasty & $32(78 \%)$ \\
\hline Cutting balloon & $7(17 \%)$ \\
\hline Restenting & $27(66 \%)$ \\
\hline Covered & $19(46 \%)$ \\
\hline Non-covered & $8(19 \%)$ \\
\hline Runoff score (Mean \pm SD) & $2.1 \pm 0.8$ \\
\hline \multicolumn{2}{|l|}{ Patency } \\
\hline \multicolumn{2}{|l|}{6 months } \\
\hline Primary & $96 \%$ \\
\hline Primary assisted & $96 \%$ \\
\hline \multicolumn{2}{|l|}{12 months } \\
\hline Primary & $84 \%$ \\
\hline Primary assisted & $90 \%$ \\
\hline \multicolumn{2}{|l|}{ Target lesion revascularization } \\
\hline 6 months & 0 \\
\hline 12 months & $10 \%$ \\
\hline Amputation & 0 \\
\hline Death & $5 \%$ \\
\hline
\end{tabular}

Catheter Cardiovasc Interv. Author manuscript; available in PMC 2013 December 01. 